Supplement of Nat. Hazards Earth Syst. Sci., 21, 2277-2284, 2021

https://doi.org/10.5194/nhess-21-2277-2021-supplement

(C) Author(s) 2021. CC BY 4.0 License.

(c) (1)

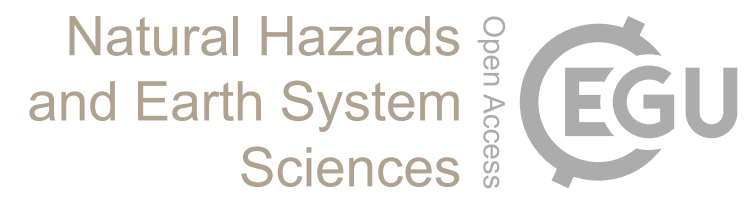

Supplement of

\title{
Space-time clustering of climate extremes amplify global climate impacts, leading to fat-tailed risk
}

\author{
Luc Bonnafous and Upmanu Lall \\ Correspondence to: Luc Bonnafous (lbonnafous@worlbank.org)
}

The copyright of individual parts of the supplement might differ from the article licence. 


\section{Supplementary Material}

\section{Figures}

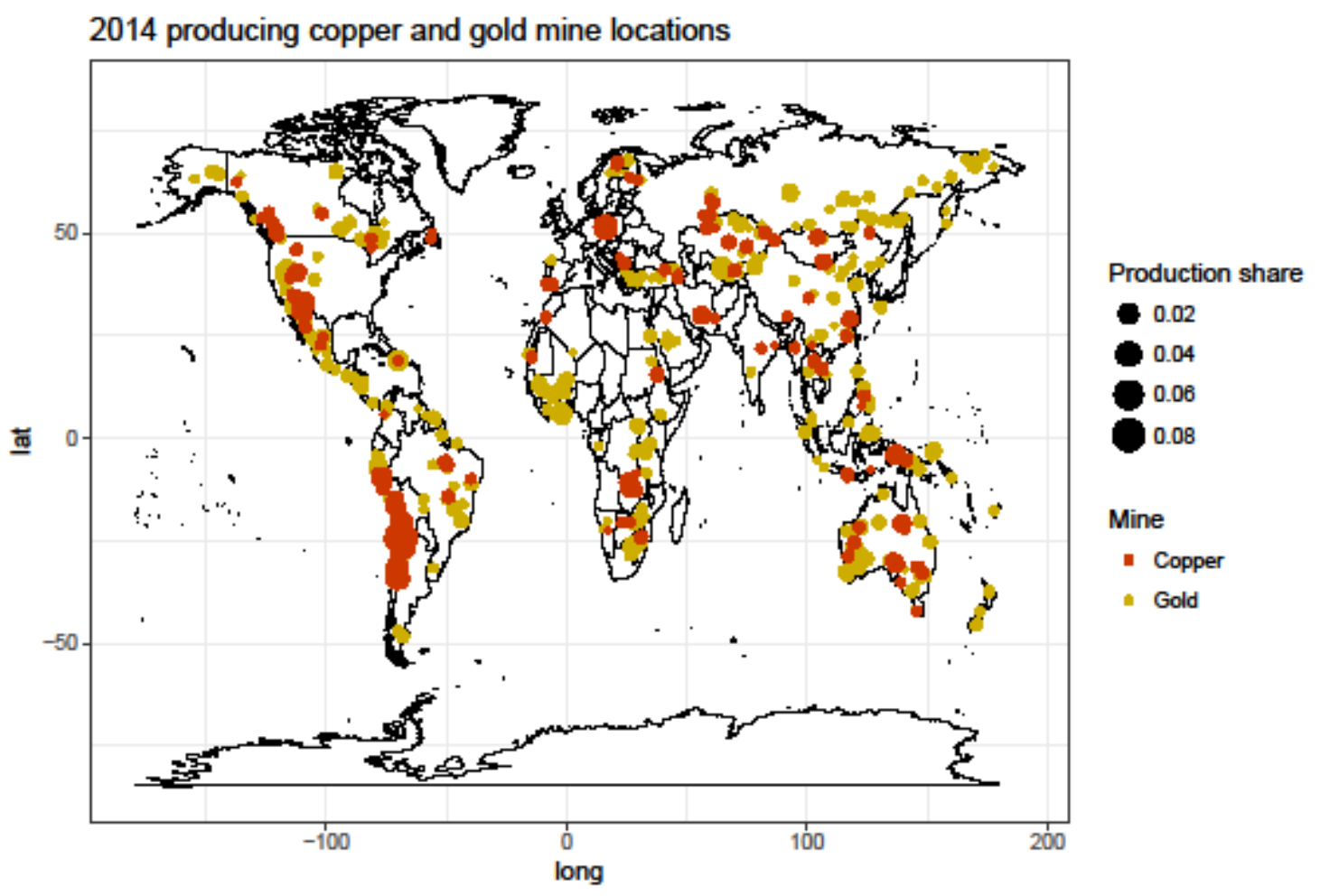

Figure S1: 2014 copper and gold producing mine locations (top) and 2014 copper and gold producing mine locations with size proportional to production (bottom) 


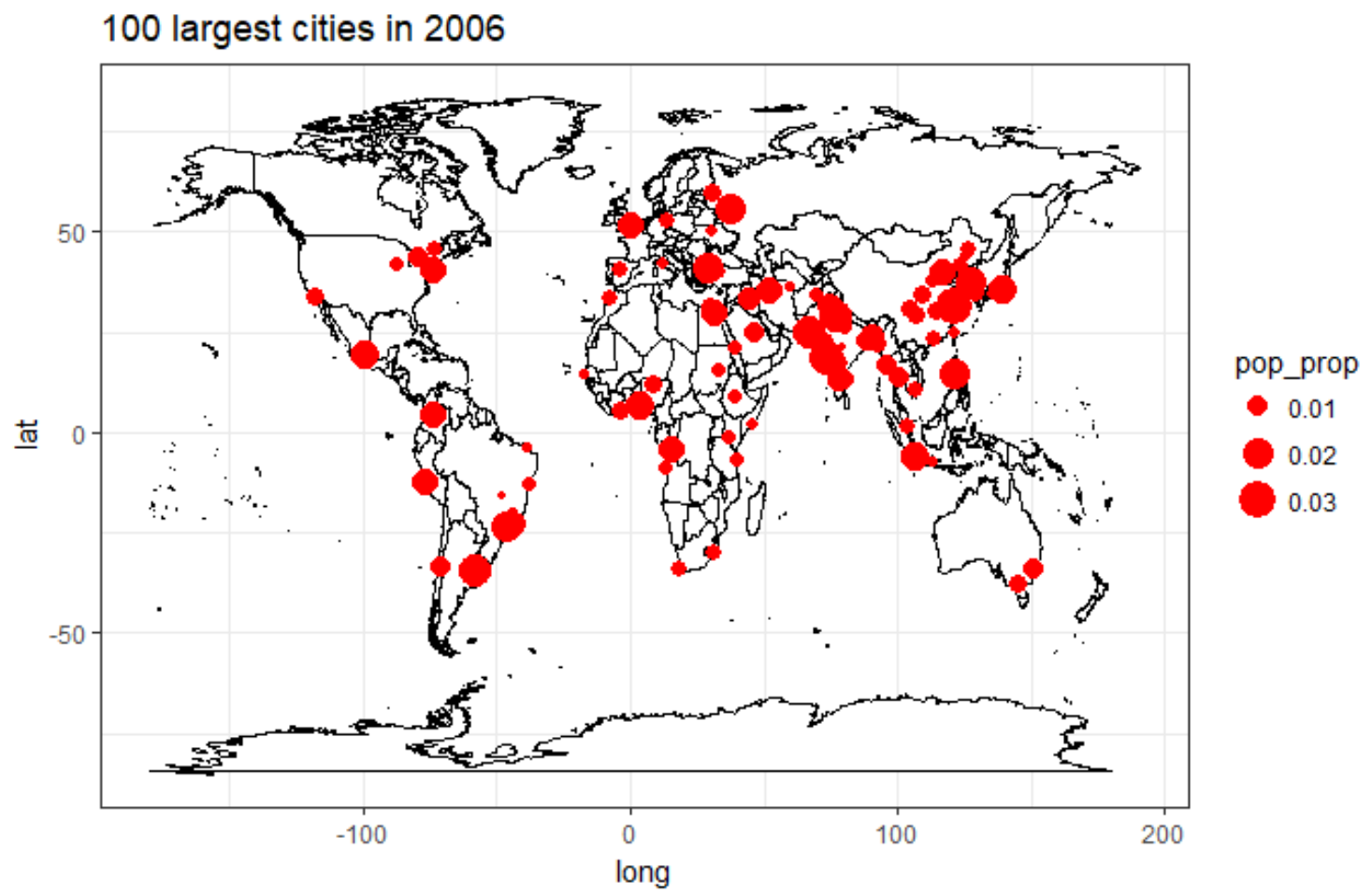

Figure S2: Location of the 100 largest cities in the world in 2006

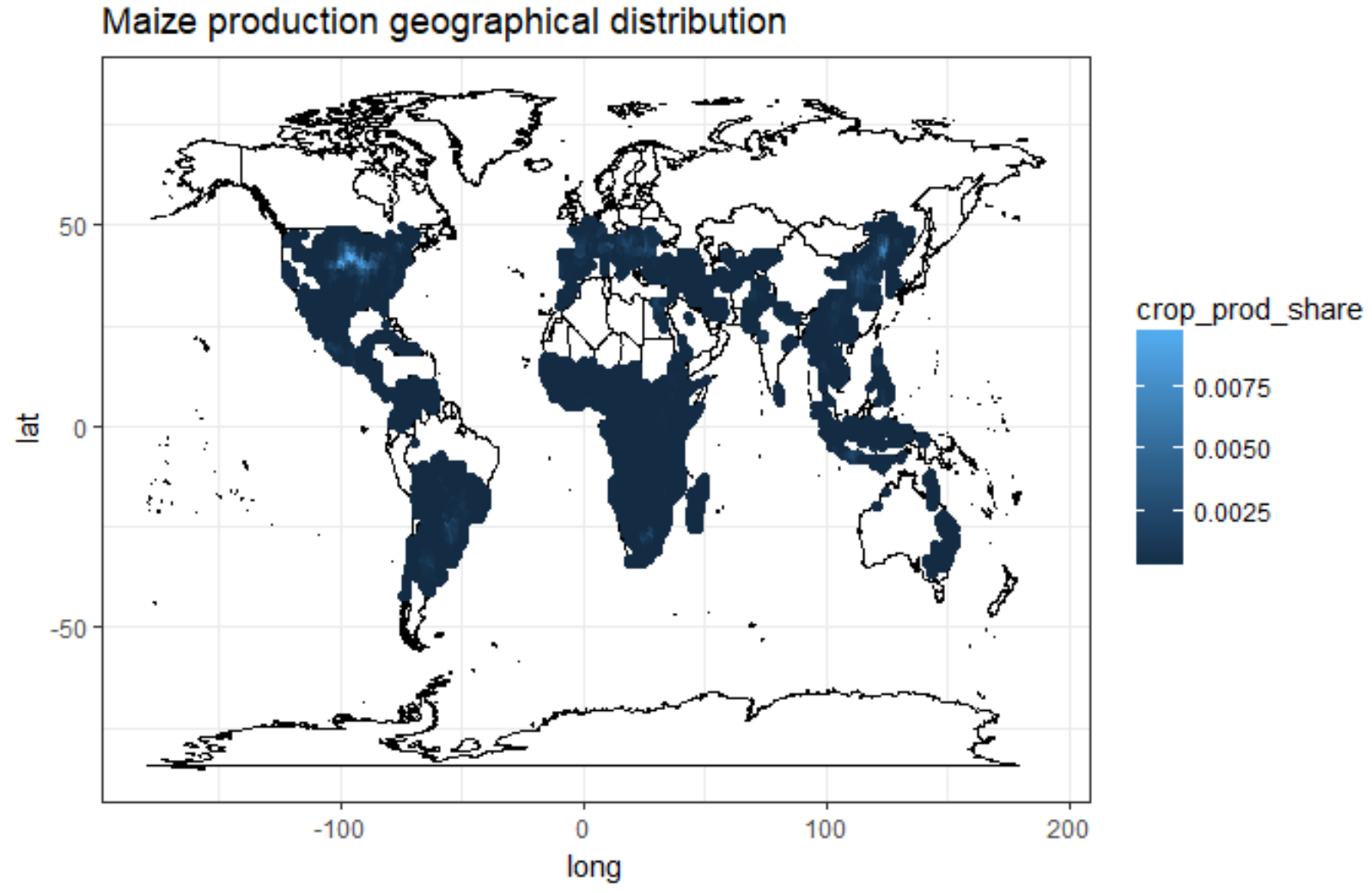

Figure S3: 2011 Maize production distribution 


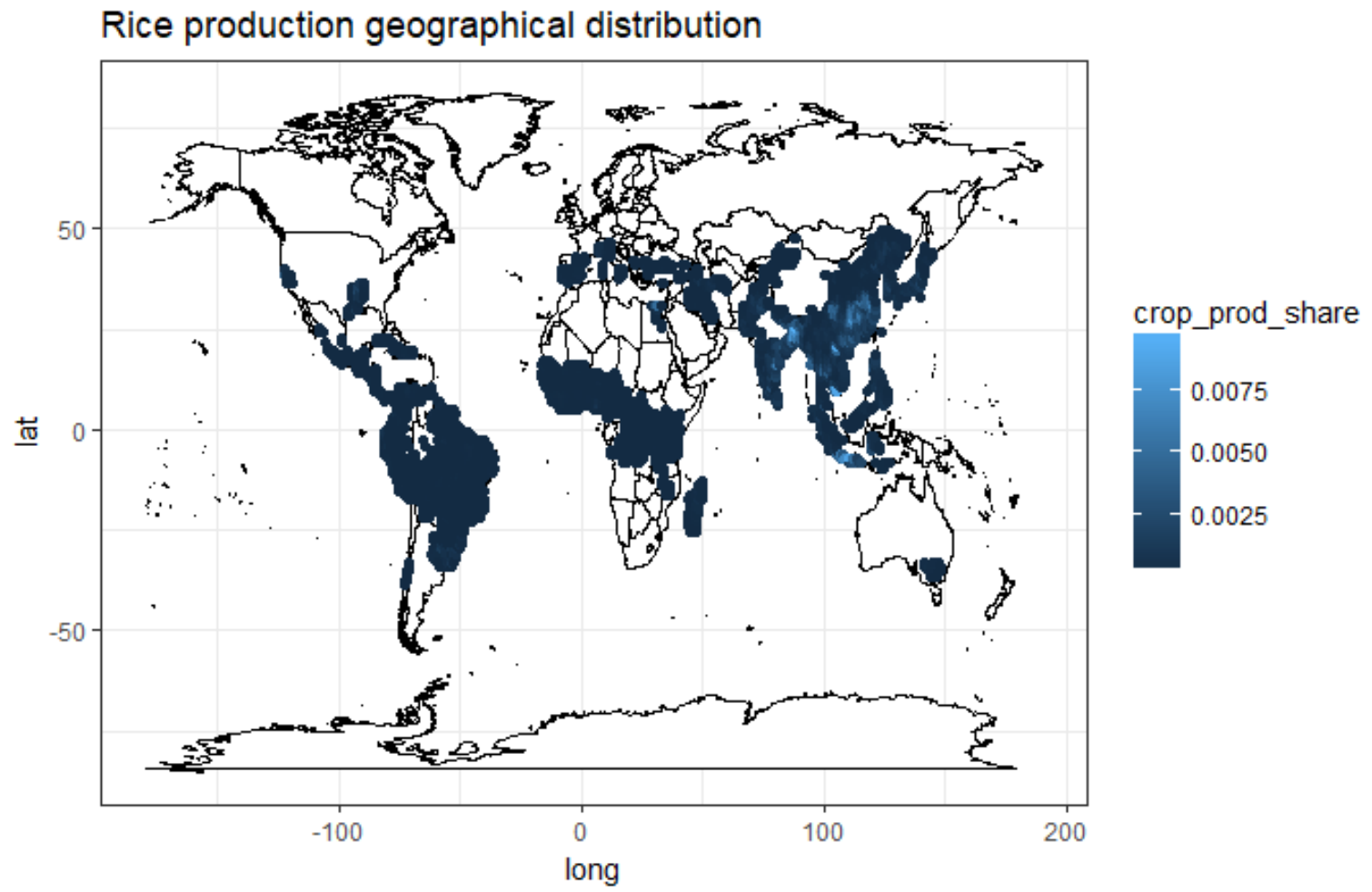

Figure S4: 2011 Rice production distribution

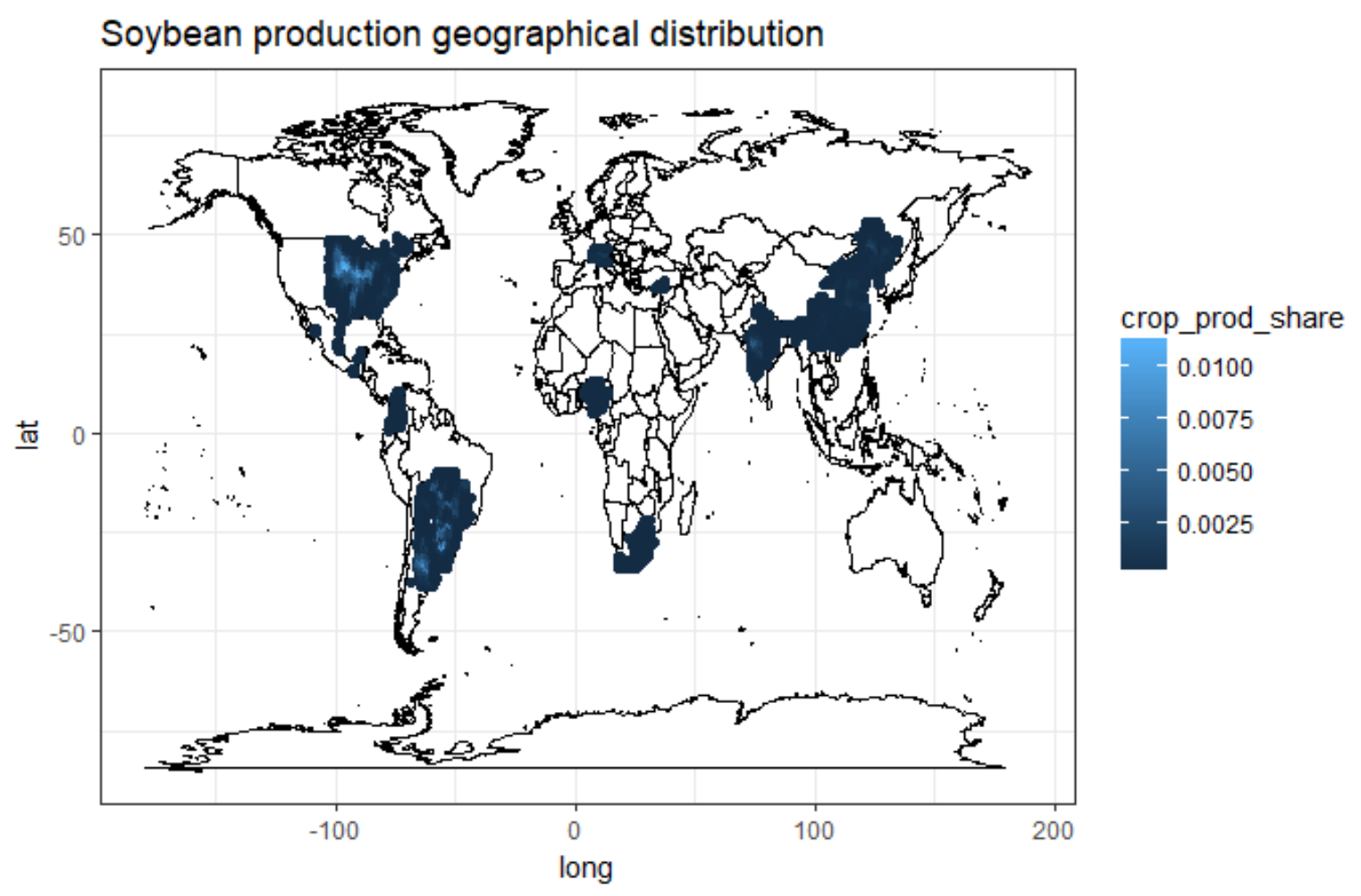

Figure S5: 2011 Soybean production distribution 


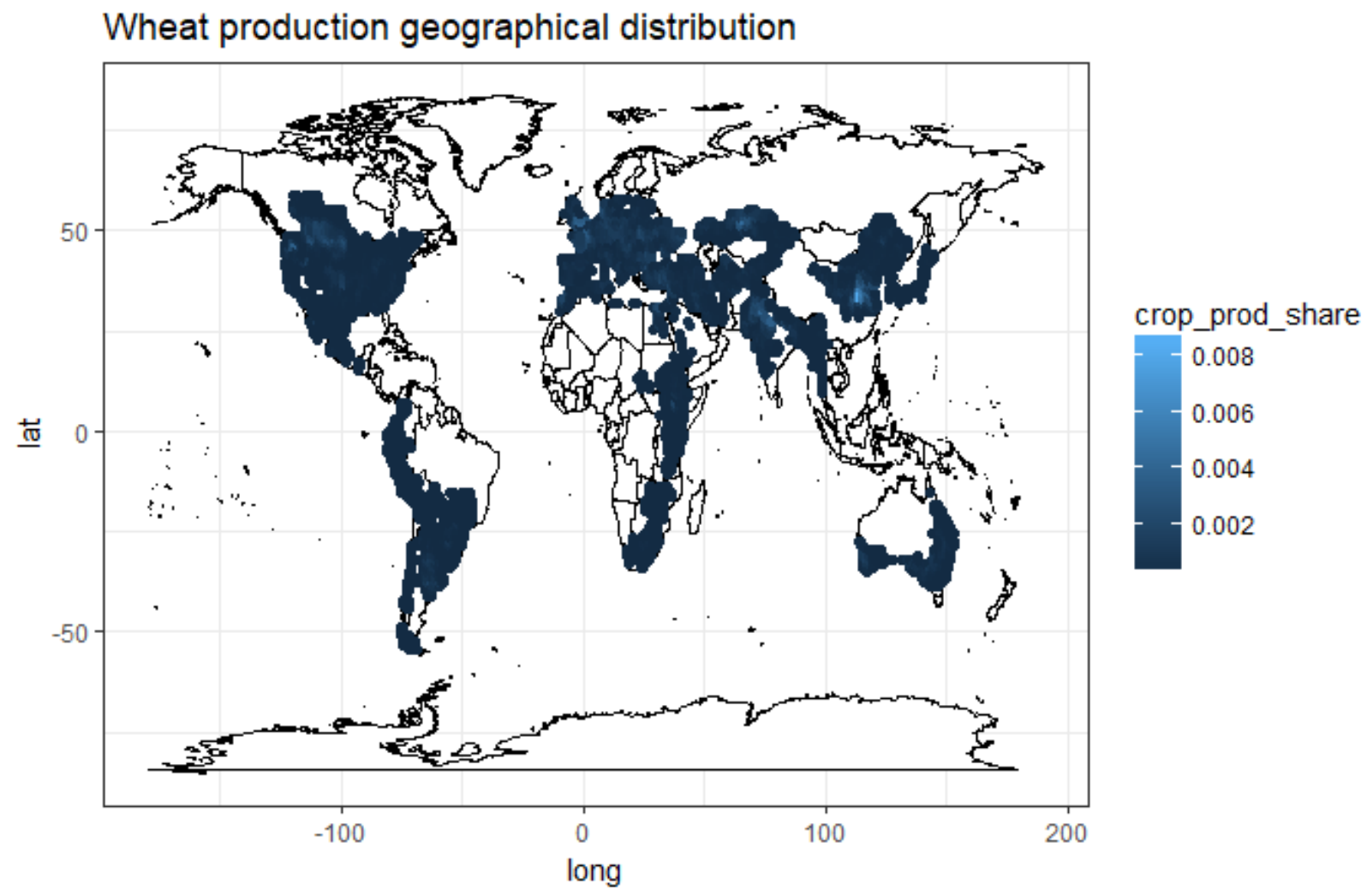

Figure S6: 2011 Wheat production distribution 
Time series of the proportion of the land area between $30^{\circ} \mathrm{N}$ and $15^{\circ} \mathrm{N}$ affected by a 12-month event with a 10-year return level
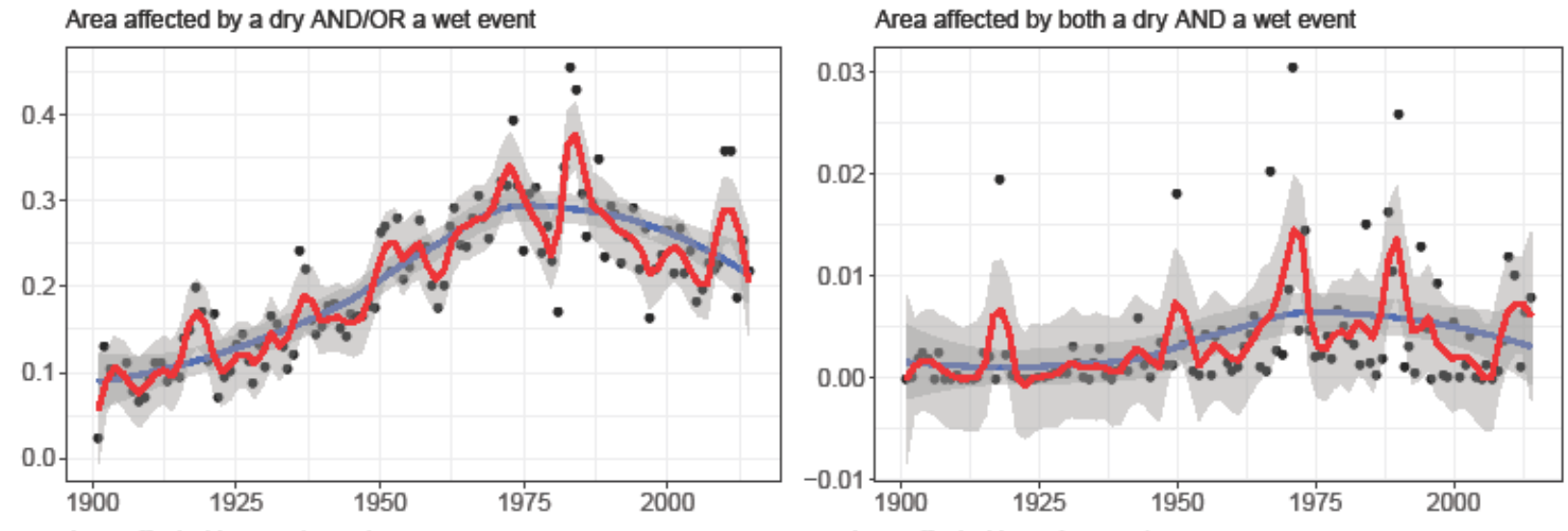

\section{Legend}

11-year smooth

85-year smooth
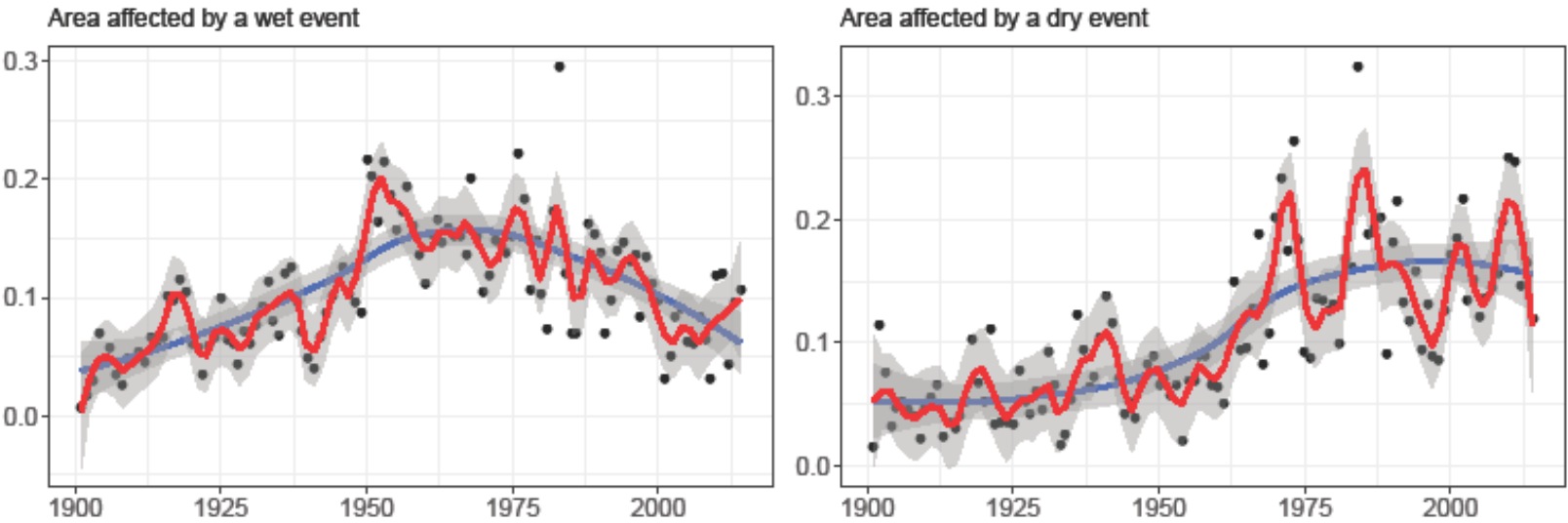

Figure S7: Northern sub-tropical area proportion affected by a 10-year, 12-month, wet or dry (top left), wet and dry (top right), wet (bottom left), and dry (bottom right) 

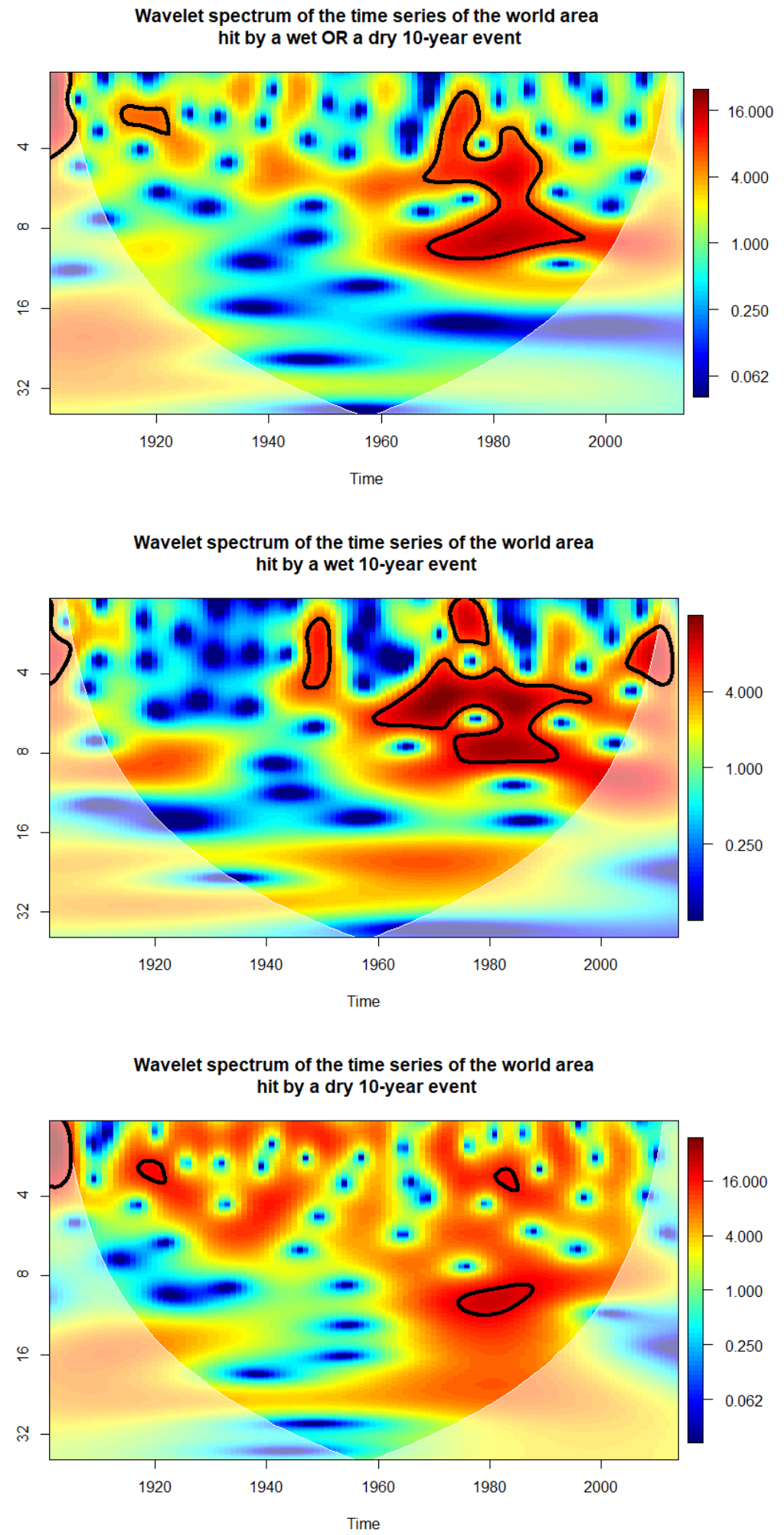

Figure S8: 2011 Wavelet spectra of the yearly time series of world areas hit by a 10-year wet or dry (top), wet (middle) or dry (bottom) event 

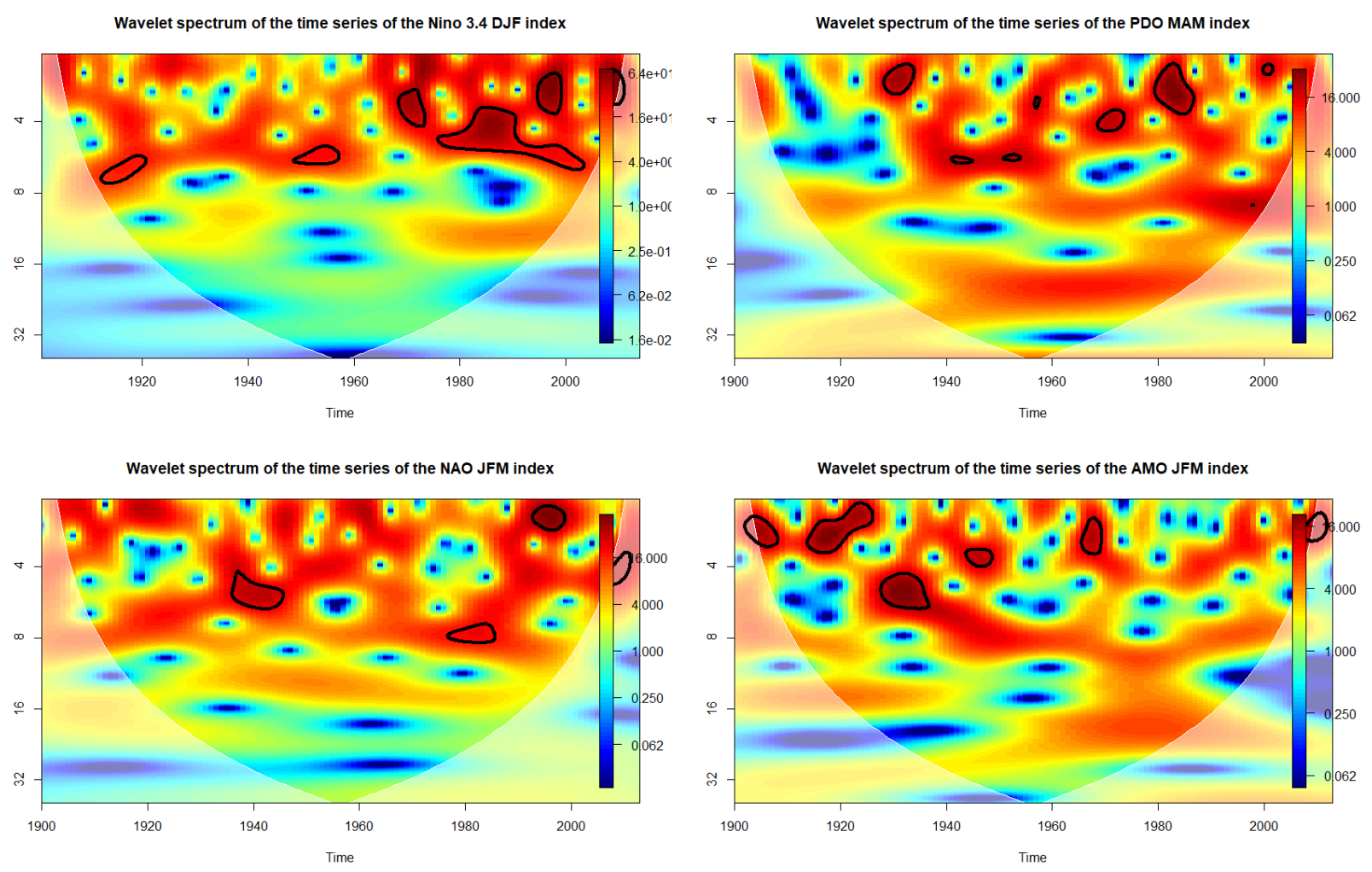

5

Figure S9: Wavelet spectra of Nino 3.4 DJF (top left), PDO MAM (top right), NAO JFM (bottom right), AMO JFM (bottom right) indexes 

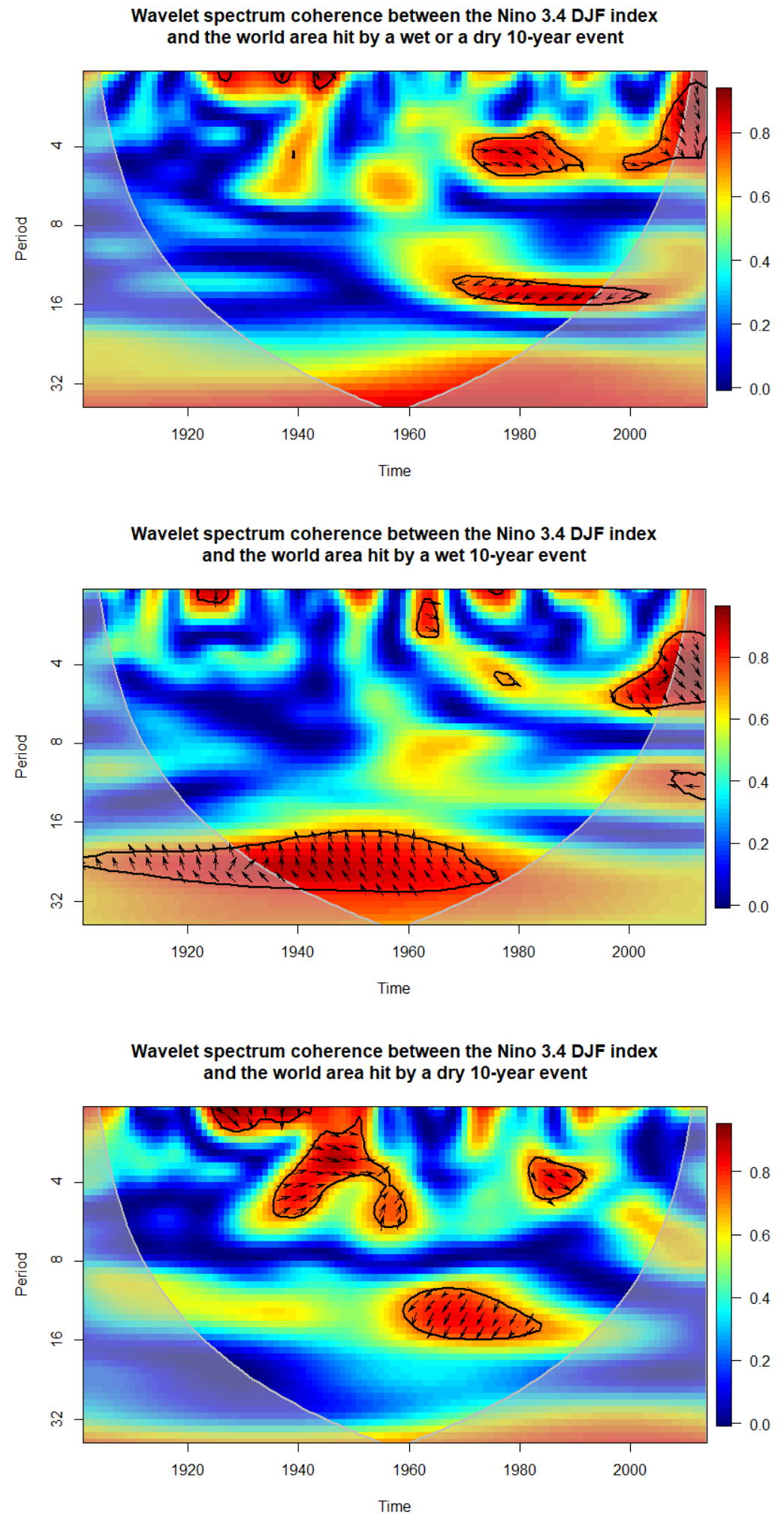

Figure S10: Wavelet coherence between time series of the Nino3.4 DJF index and world areas

hit by a 10-year wet or dry (top), wet (middle) or dry (bottom) event 

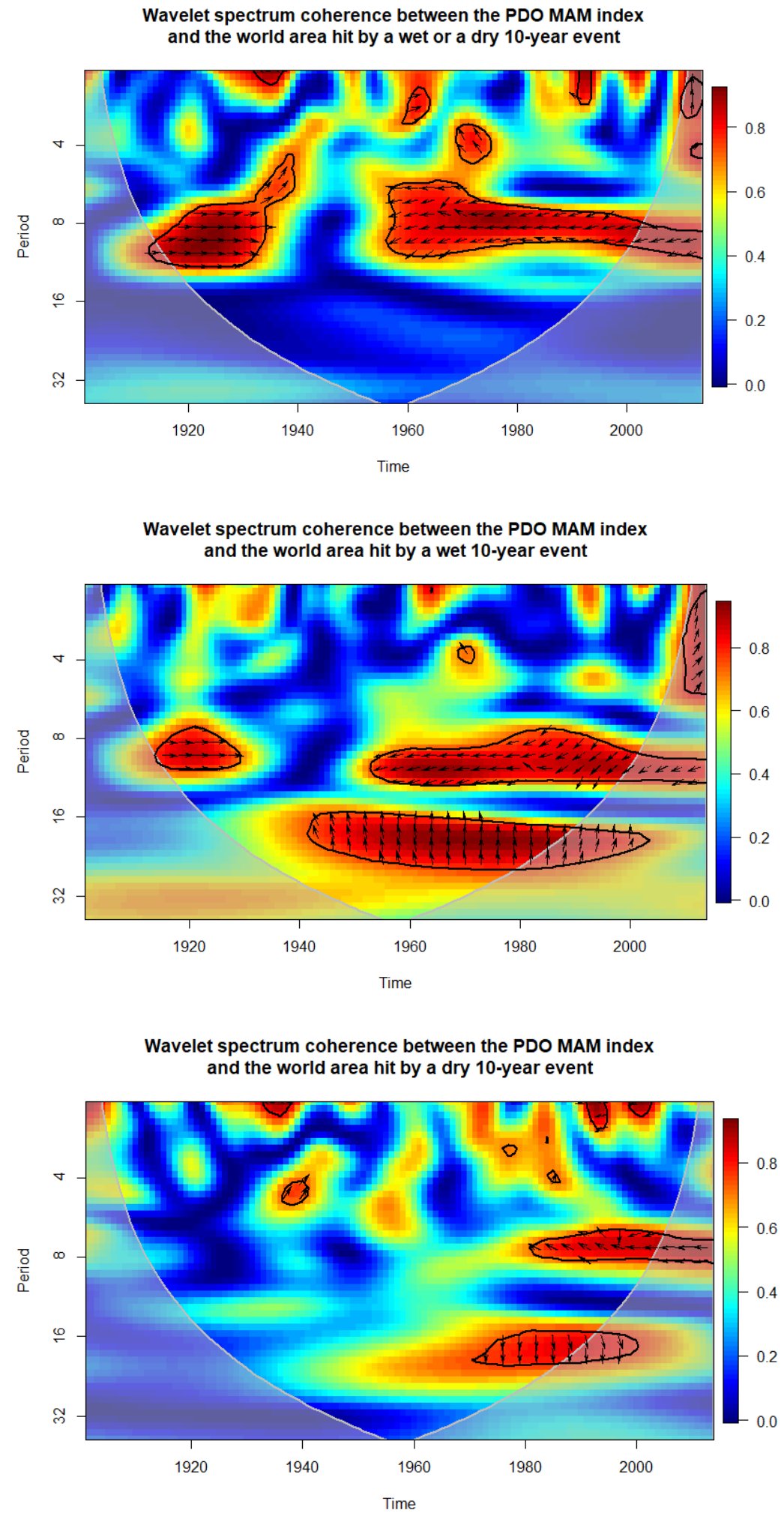

Figure S11: Wavelet coherence between time series of the PDO MAM index and world areas hit

by a 10-year wet or dry (top), wet (middle) or dry (bottom) event 

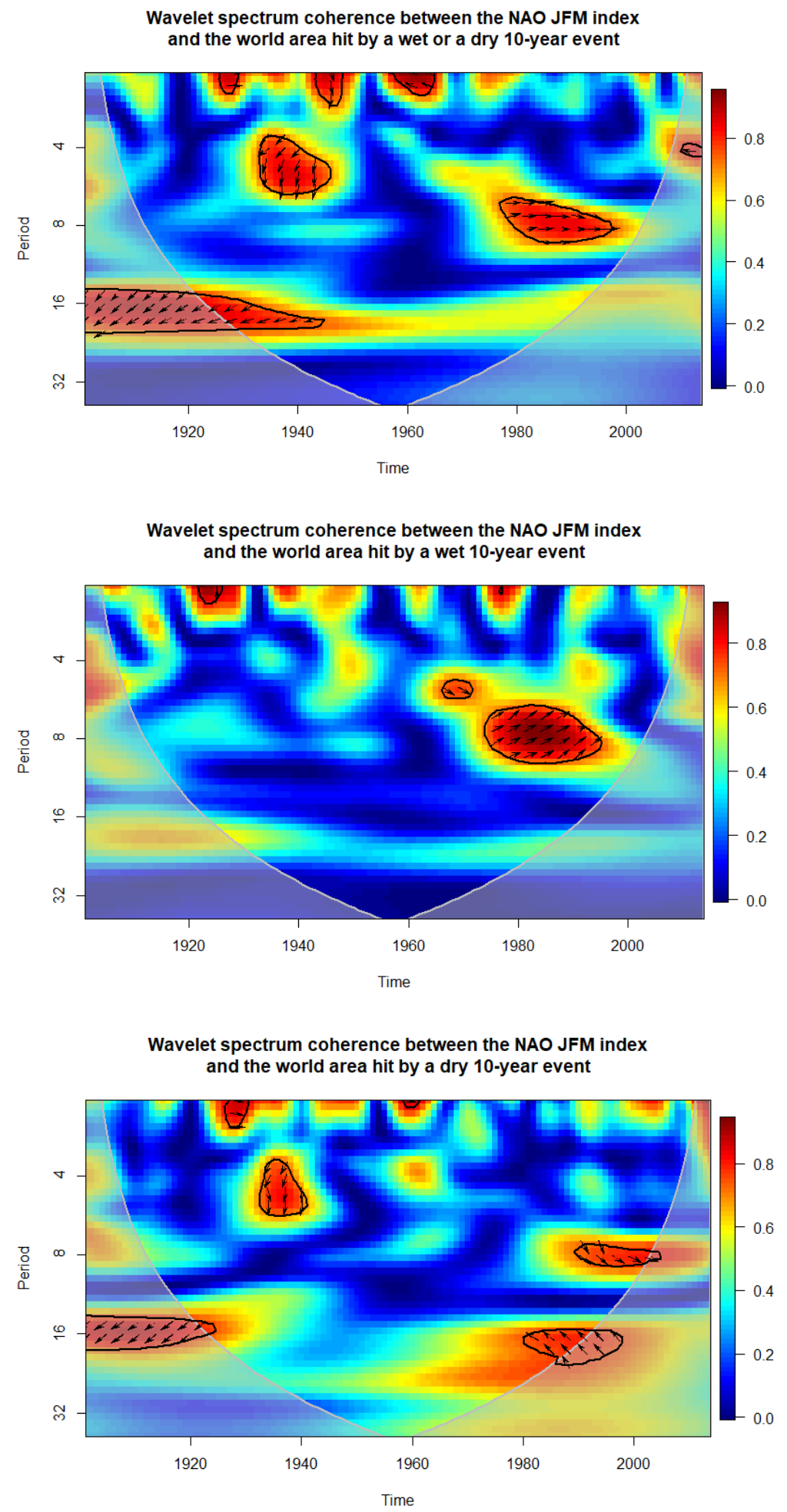

Figure S12: Wavelet coherence between time series of the NAO JFM index and world areas hit

by a 10-year wet or dry (top), wet (middle) or dry (bottom) event 

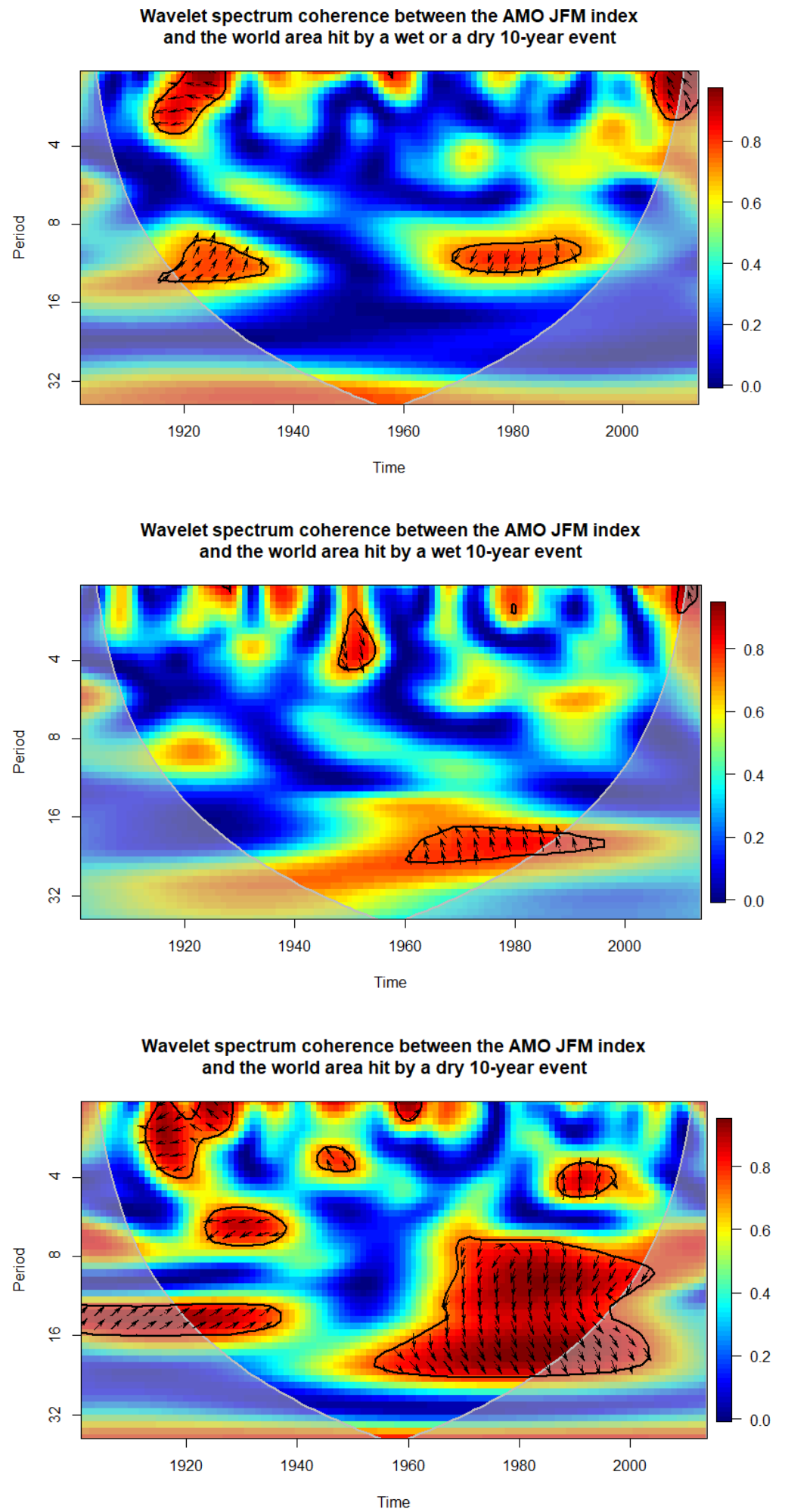

Figure S13: Wavelet coherence between time series of the AMO JFM index and world areas hit

by a 10-year wet or dry (top), wet (middle) or dry (bottom) event 

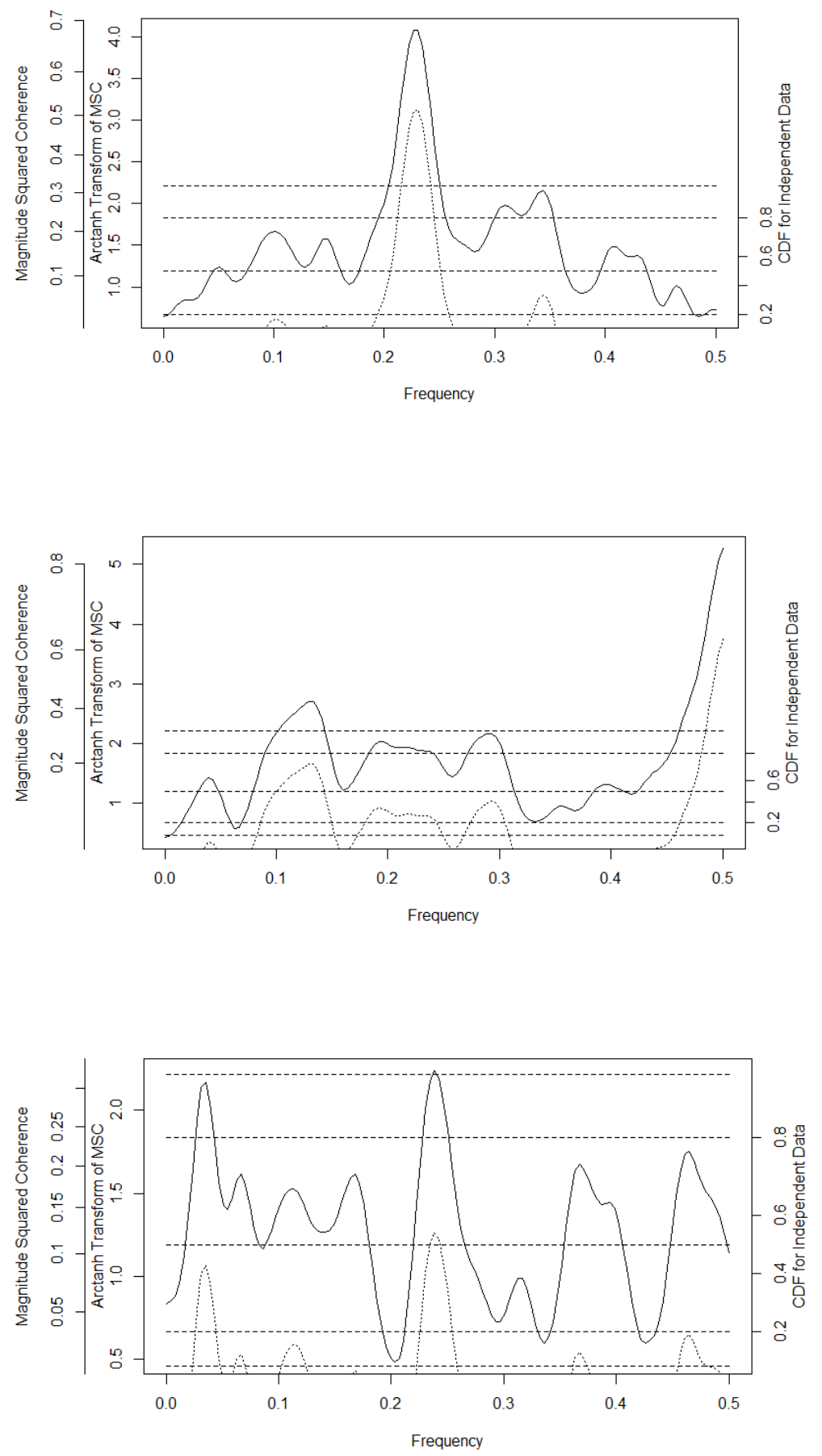

Figure S14: MTM spectrum coherence between the time series of world area hit by a wet or dry ten-year event and the Nino 3.4 DJF index (top), the NAO DJFM index (middle) and the PDO MAM index (bottom) 
Time series of the proportion of 2014 copper production affected by a 12-month event with a 10-year return level
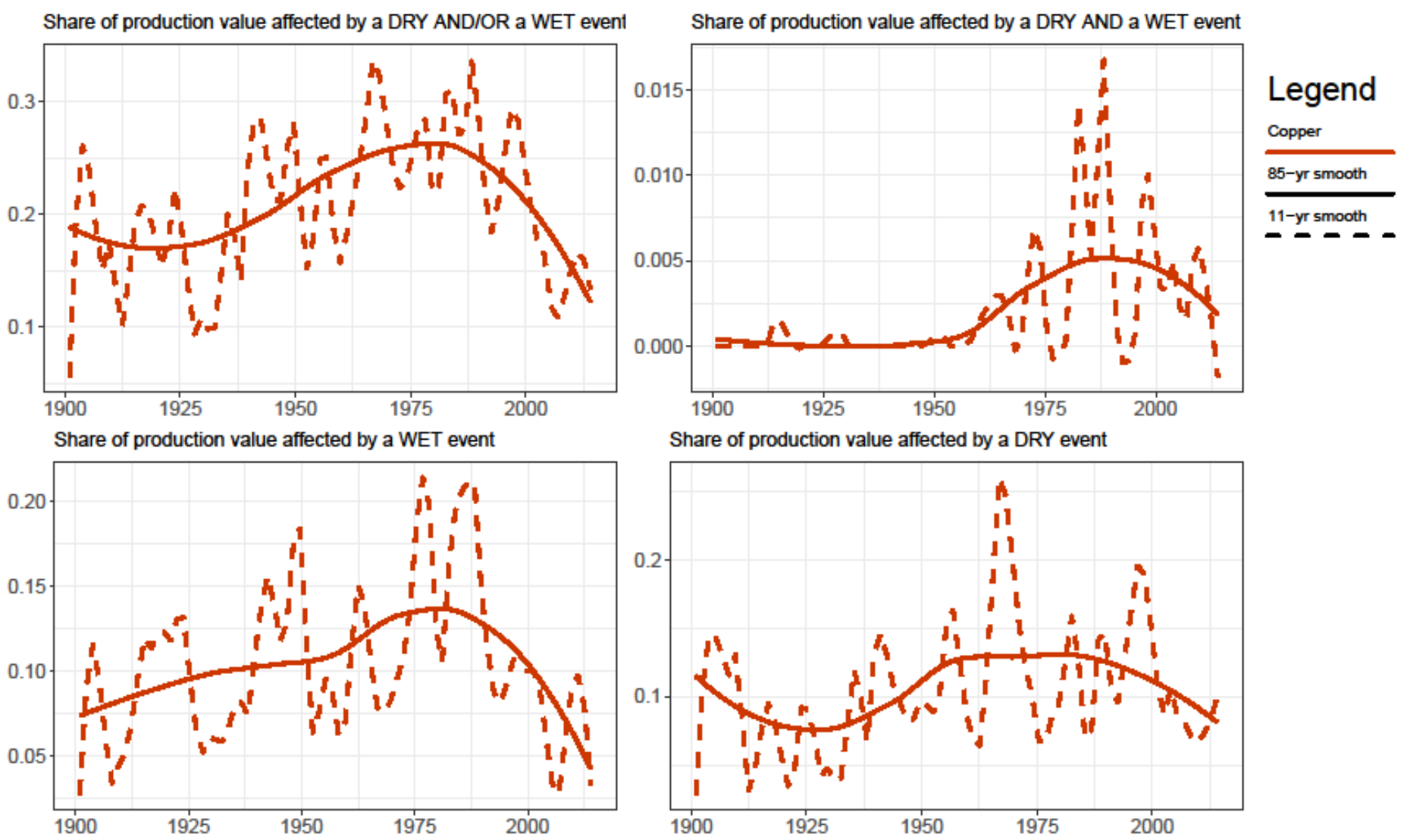

Figure S15: Time series of the proportion of the 2014 copper production affected by a dry or wet event 
Wavelet analysis of the copper mine exposure time series

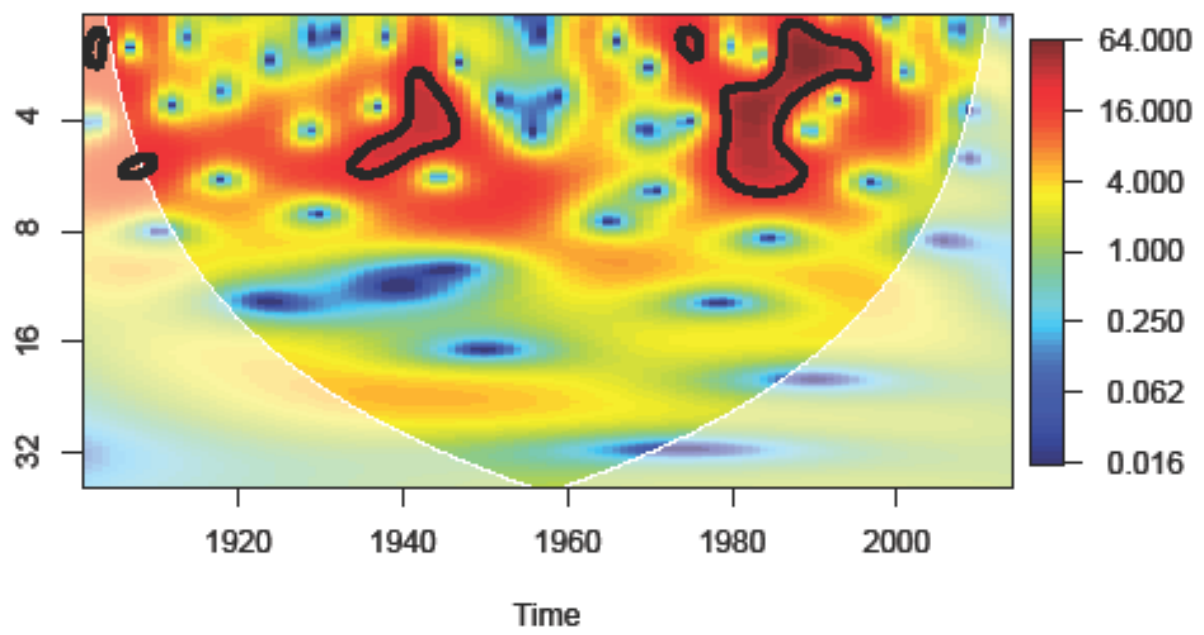

Figure S16: Wavelet analysis of the copper mining exposure time series

\section{World time series}
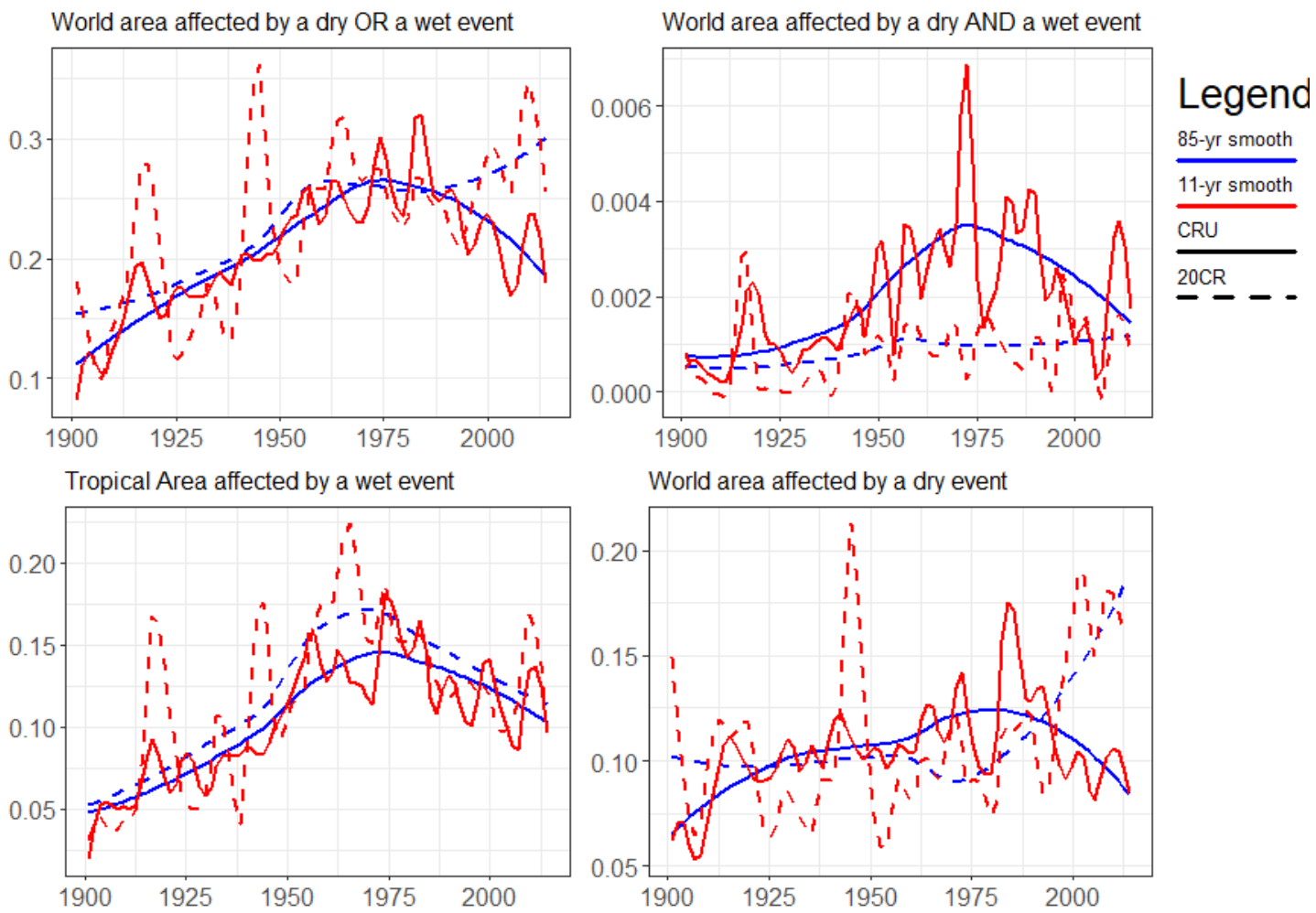

Figure S17: Fraction of land area hit by a 10-year event according to CRU and 20CR SPEI data. 


\section{Time series of the proportion of the World land area affected by a 12-month event with a 10-year return level}
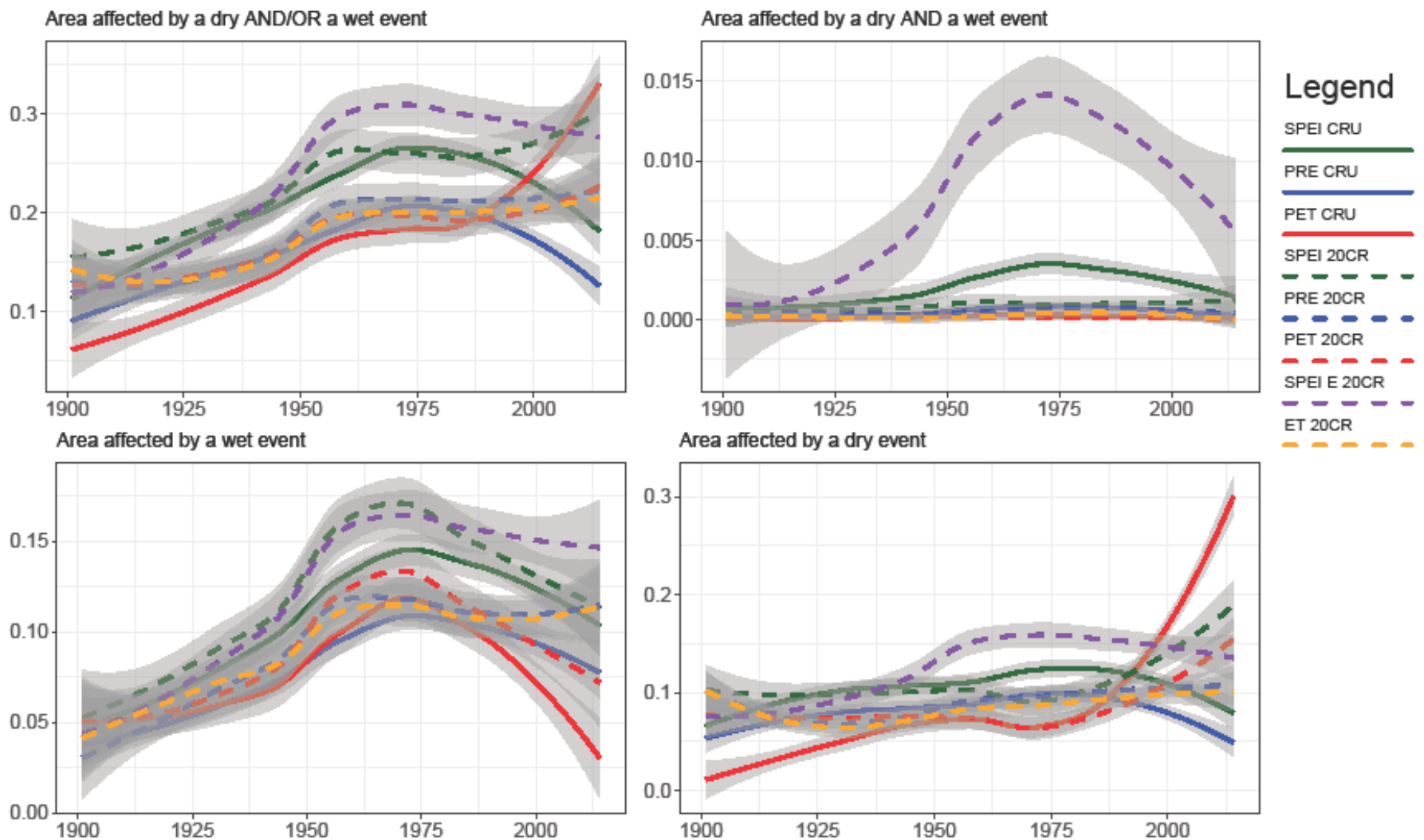

Figure S18: Fraction of land area hit by a 10-year event according to CRU and 20CR data. 85year smoothing trend of the fraction of land area hit by a 10-year event based on SPEI, precipitation (PRE), potential evapotranspiration (PET), according to CRU and 20CR data, and to evapotranspiration $(E)$ and a version of the SPEI using evapotranspration instead of potential evapotranspiration (SPEI E) according to 20CR. 